\title{
Hyperbaric-oxygen treatment: An adjunctive therapy in acute renal failure due to crush injury
}

\author{
Rumeyza Kazancioglu ${ }^{1^{*}}$, Cenk Gulgun ${ }^{2}$, Salih Aydin $^{2}$, Nilgun Aysuna ${ }^{3}$, Semra Bozfakioglu ${ }^{3}$, \\ Mehmet S. Sever ${ }^{3}$ \\ ${ }^{1}$ Department of Nephrology, Faculty of Medicine, Bezmialem Vakif University, Istanbul, Turkey; \\ *Corresponding Author: rkazancioglu@,bezmialem.edu.tr \\ ${ }^{2}$ Department of Undersea and Hyperbaric Medicine, Istanbul Medical Faculty, Istanbul University, Istanbul, Turkey \\ ${ }^{3}$ Department of Nephrology, Istanbul Medical Faculty, Istanbul University, Istanbul, Turkey
}

Received 25 April 2012; revised 30 May 2012; accepted 14 June 2012

\section{ABSTRACT}

Objective: Major seismic events leave their survivors trapped under the rubble leading to extensive muscle damage and its devastating sequale of hemodynamic and metabolic disturbances and acute renal failure. Hypoxemia aggravated during each hemodialysis (HD) session is important in acute renal failure patients with massive tissue injury. We retrospectively analyzed the adjunctive role of hyperbaric-oxygen (HBO) therapy in patients treated with HD for acute renal failure due to crush injury in terms of dialysis duration. Patients and Methods: 16 patients admitted after the 1999 Marmara earthquake to Istanbul Faculty of Medicine were treated with HBO. Only 8 (2 M, 6 F, mean age: $24.8+7.3$ years) of them had required HD treatment. 29 (16 M, 13 F, mean age: $34.6+12.9$ years) crush syndrome patients treated with HD but not with HBO were taken as controls and the clinical and laboratory data of the two groups were compared. Results: The mean duration time under the rubble for the HBO group was 9.4 +3.2 hours. Mainly lower extremity fasciotomies were performed at $15.6+14.8$ hours after extrication. There were no amputations in this group. There were three amputations in the control group. The mean number of HD sessions was 9.2 +6.7 /patient for $10.9+9.6$ days until renal functions recovered and the patients had $27.4+15.6$ HBO sessions until the recovery of their lesions. There were no correlations between the number of HBO sessions and any laboratory parameter nor the number of HD sessions. There was no statistical difference in the need for HD between the HBO and control group. Conclusions: Our results could not demonstrate a significant effect of HBO treatment in terms of HD duration; how- ever, the valuable contribution of the HBO treatment was to increase the salvage of crushed limbs.

Keywords: Hyperbaric Oxygen Treatment; Crush Injury; Hemodialysis

\section{INTRODUCTION}

Acute renal failure is a life threatening disorder with high mortality despite the introduction of hemodialysis and many modern supportive therapies. Though a modest improvement in mortality has been achieved during the last 20 years, simple acute renal failure without comorbid conditions has about 7\% - 23\% mortality [1].

Prognosis is worsened if other organ systems are affected by the primary event as in the case of acute renal failure related to crush syndrome [2]. Crush syndrome is the systemic manifestation of muscle injury caused by prolonged limb compression sustained in crush injury and is characterized by hypovolemic shock, hyperkalemia, acute renal failure and muscle necrosis [2]. The mortality rate of crush syndrome associated with acute renal failure remains high despite major advances in critical care, reaching 50\% - 60\% in complicated cases [3]. This rate was reported to be $17.2 \%$ among the dialyzed victims after the Marmara earthquake [3].

For the treatment of crush victims when indicated, hemodialysis (HD) is a life saving treatment modality and should be initiated as soon as possible. The HD should always be initiated in the presence of serum potassium $\geq 6.5 \mathrm{mmol} / 1$ or quickly rising serum potassium levels not responding to other measures, Acidosis and BUN level $\geq 100 \mathrm{mg} / \mathrm{dl}$ or serum creatinine $\geq 8 \mathrm{mg} / \mathrm{dl}$ are further indications for HD. Even if the before mentioned laboratory findings are not present or unavailable, clinical symptoms of renal failure or uremic retention such as volume overload, pericarditis, coagulopathy and an otherwise unexplained decline in mental status constitute the 
other indications for dialysis [1-3]. On the other hand, one should not forget that, hypoxemia aggravated during each HD session is important in this particular group of patients with massive crush injuries [4-6]. Hypoventilation remains the major cause of hypoxemia in HD [6]. This hypoventilation is mainly due to $\mathrm{CO}_{2}$ consumption during acetate metabolism (acetate dialysis), or alkalinization of the blood (bicarbonate dialysis) [4-6].

Hyperbaric-oxygen (HBO) therapy may simultaneously provide beneficial effect directed at many components responsible for ischemia-reperfusion injury, including the neutrophil, endothelium, inflammatory mediators, lipid peroxidation, cellular energetics and microvascular blood flow [7-11]. It has been reported that HBO treatment may modulate kidney function in rats with sepsis, rats with adriamycin-induced nephrotic syndrome and experimental cyclosporine nephrotoxicity [12]. Recently, Solmazgul et al. [13] demonstrated that HBO attenuated the elevation in plasma creatinine and histological damage in Sprague-Dawley rats subjected to renal ischemia/ reperfusion injury. Moreover, HBO treatment has been reported to be beneficial in the management of the muscle compartment syndrome, a devastating complication of crush syndrome, where kidney function is often impaired [14-19].

In this study, we retrospectively analyzed the adjuncttive role of HBO therapy in patients treated with intermittent HD for crush syndrome related acute renal failure.

\section{MATERIAL AND METHODS}

After the Marmara Earthquake, one of the greatest disasters of the previous decade, registering 7.4 on the Richter Scale, 960 injured patients were admitted to the emergency units of Istanbul Medical Faculty and 321 $(33 \%)$ of them were hospitalized. Sixty (18\%) patients (30 male, 30 female) with a mean age of $31.3+13.8$ years fullfilling the criteria for crush syndrome (urine output $<400 \mathrm{ml} /$ day and/or BUN $>40 \mathrm{mg} / \mathrm{dl}$, serum creatinine $>2.0 \mathrm{mg} / \mathrm{dl}$, uric acid $>8.0 \mathrm{mg} / \mathrm{dl}$, potassium $>$ $6.0 \mathrm{mEq} / \mathrm{L}$, phosphorus $>8.0 \mathrm{mg} / \mathrm{dl}$ and/or serum total calcium $<8.0 \mathrm{mg} / \mathrm{dl}$ ) were the subject of this study.

Among those patients, 16 patients received HBO therapy. Only 8 of them required HD treatment (Group I). Twenty-nine patients requiring HD treatment, but not HBO therapy, were taken as controls (Group II). Hyperbaric-oxygen therapy was initiated for fasciotomized patients in the presence of necrosis, edema and/or wound infection. The remaining patients did not need any HD or HBO treatments.

Data concerning the patients' demographics, physical and laboratory findings, treatment modalities and outcomes were collected retrospectively from the patients' files.
In each patient, blood biochemistry was determined after the physical examination both at admission and thereafter. Besides supportive therapies fasciotomies were carried out in patients according to the indications of clinical findings, since intracompartment pressure could not be measured.

Bicarbonate HD treatment was performed intermittently for $3-4$ hours, with tight heparinization protocol, until the recovery of renal function in patients with acute renal failure. The recovery of renal function was taken as normalization of urinary volume in a patient with improving serum biochemical values in the absence of fluid overload. Vascular access for this treatment was maintained by double lumen catheters, which were inserted percutaneously to central veins.

A session of HBO lasted 90 minutes in a closed multiplace chamber where all the patients breathed $100 \%$ oxygen at 2.4 ATA through a face mask after the HD session when applicable as suggested by UHMS protocol $[20,21]$. Side effects of HBO therapy were classified as pulmonary or central nervous system oxygen toxicity and middle ear barotrauma. The HBO therapy was continued until recovery of necrosis, edema and/or wound infection.

Descriptive statistics of all numeric variables, includeing mean, standard deviation and minimum and maximum values were calculated. Statistical significance was considered at a $\mathrm{p}$ value $<0.05$.

\section{RESULTS}

Group I consisted of 2 male and 6 female patients whose mean age was $24.8+7.3(19-38)$ years. Group II had 16 male and 13 female patients with a mean age of $34.6+12.9(16-62)$ years $(\mathrm{p}=0.005)$.

The mean duration of time under the rubble for Group I was $9.4+3.2(2.5-12)$ hours. All of the patients had lower extremity fasciotomies which were performed at $15.6+14.8(4-96)$ hours after extrication. There were no amputations in this group. The admission laboratory values of Group I are presented in Table 1. On the other hand, the mean duration of time under the rubble was 8.5 \pm 3.9 (4 - 19) hours in Group II. There was no statistical difference between the two groups in terms of time under the rubble $(p=0.53)$. Five patients did not have any fasciotomies and the rest (83\%) had fasciotomies performed in 41 different anatomical sites. There were also three amputations in this group. All of the patients with amputations had already fasciotomies.

There was no statistical difference in serum potassium $(\mathrm{K})$, creatinine phosphokinase $(\mathrm{CPK})$ and alanine aminotransferase (ALT) levels, the duration time under the rubble and the need for HD between the Group I and Group II (Table 2). 
Table 1. The laboratory parameters of Group I at admission.

\begin{tabular}{lll}
\hline \multicolumn{1}{c}{ Serum } & \multicolumn{1}{c}{ Mean } & \multicolumn{1}{c}{ Range } \\
\hline Creatinine, $\mathrm{mg} / \mathrm{dl}$ & $3.9+1.7$ & $2.7-7.7$ \\
Potassium, $\mathrm{mEq} / \mathrm{L}$ & $4.9+1.4$ & $3.5-7.4$ \\
Creatinine phosphokinase, $\mathrm{iu} / \mathrm{L}$ & $20240.5+29203.6$ & $374-68715$ \\
Alanine aminotransferase, $\mathrm{iu} / \mathrm{L}$ & $389.8+487.3$ & $5-1301$ \\
Albumin, $\mathrm{g} / \mathrm{dl}$ & $2.3+0.5$ & $1.7-2.5$ \\
Leucocyte, $/ \mathrm{mm}^{3}$ & $16700 \pm 7066$ & $5000-12000$ \\
Albumin, $\mathrm{g} / \mathrm{dl}$ & $2.3+0.5$ & $1.7-2.5$ \\
\hline
\end{tabular}

Table 2. Comparison between Group I and Group II.

\begin{tabular}{llll}
\hline & \multicolumn{1}{c}{ Group I $(\mathrm{n}=8)$} & \multicolumn{1}{c}{ Group II $(\mathrm{n}=29)$} & \multicolumn{1}{c}{$\mathrm{p}$} \\
\hline DUR, hours & $9.4 \pm 3.2$ & $8.5 \pm 3.9$ & $\mathrm{NS}$ \\
UO, ml/day & $862.5 \pm 1378.6$ & $871.2 \pm 2031.3$ & $\mathrm{NS}$ \\
BP, mmHg & $125.7 \pm 26.1 / 78.1 \pm 14.6$ & $145 \pm 30.1 / 85.6 \pm 18.8$ & $\mathrm{NS}$ \\
$\mathrm{Htc}, \%$ & $29.8 \pm 8.9$ & $27.0 \pm 7.6$ & $\mathrm{NS}$ \\
$\mathrm{Cr}, \mathrm{mg} / \mathrm{dl}$ & $3.9 \pm 1.7$ & $6.1 \pm 3.3$ & 0.02 \\
$\mathrm{~K}, \mathrm{mEq} / \mathrm{L}$ & $4.9 \pm 1.4$ & $5.0 \pm 1.4$ & $\mathrm{NS}$ \\
$\mathrm{CPK}, \mathrm{iu} / \mathrm{L}$ & $20240.5 \pm 29203.6$ & $23336.6 \pm 26810.5$ & $\mathrm{NS}$ \\
$\mathrm{ALT}, \mathrm{iu} / \mathrm{L}$ & $389.8 \pm 487.3$ & $231.1 \pm 330.3$ & $\mathrm{NS}$ \\
HD ses/pt & $9.3 \pm 6.7$ & $9.4 \pm 6.8$ & $\mathrm{NS}$ \\
HD dr, days & $10.9 \pm 9.6$ & $10.4 \pm 8.5$ & $\mathrm{NS}$ \\
\hline
\end{tabular}

DUR: duration time under the rubble; UO: urine output; BP: blood pressure; Htc: hematocrit; Cr: creatinine; ses/pt: session/patient; dr: duration.

In Group I, the mean HD session/patient was 9.2 + 6.7 for $10.9+9.6$ days until the renal functions recovered and the patients had a mean of $27.4+15.6(2-54) \mathrm{HBO}$ sessions till the recovery of their fasciotomy lesions (Table 3). In Group II, the mean HD session/patient was 9.4 \pm 6.8 for $10.4 \pm 8.5$ days.

During the hospitalization group I patients received a mean of $27.3 \pm 43.1(3-124)$ units of blood and $39.8 \pm$ 35.9 (8 - 96) units of fresh frozen plasma. Group II patients received $17.4 \pm 21.9(1-76)$ units of blood and $38.5 \pm 49.8$ ( 1 - 176) units of fresh frozen plasma which was not statistically different from group I ( $p=0.58$ and $\mathrm{p}=0.95$, respectively ).

There were no correlations between the number of HBO sessions and any admission laboratory parameters nor the number of HD sessions. The total number of HBO sessions correlated negatively with initial urine output $(\mathrm{r}=-0.61)$ and positively with blood transfusions $(\mathrm{r}=0.79)$ and fresh frozen plasma administrations $(\mathrm{r}=$ $0.59)$. None of the patients in Group I had a documented side effect of HBO treatment.
Table 3. Hyperbaric oxygen treatment details.

\begin{tabular}{cccc}
\hline Patients & $\begin{array}{c}\text { Gender/Age, } \\
\text { years }\end{array}$ & $\begin{array}{c}\text { No of } \\
\text { Fasciotomies }\end{array}$ & $\begin{array}{c}\text { No of HBO } \\
\text { sessions }\end{array}$ \\
\hline 1 & F/38 & 1 & 42 \\
2 & F/23 & 1 & 2 \\
3 & F/19 & 2 & 4 \\
4 & F/22 & 1 & 25 \\
5 & F/19 & 1 & 26 \\
6 & $\mathrm{~F} / 24$ & 1 & 54 \\
7 & $\mathrm{M} / 34$ & 1 & 22 \\
8 & $\mathrm{M} / 19$ & 1 & 25 \\
\hline
\end{tabular}

One $(12.5 \%)$ patient in Group I died due to hydrocephalus and $6(20.6 \%)$ patients in Group II died while in the hospital $(p=0.58)$. Four of the patients died due to sepsis and the remaining due to ARDS. All the other patients regained normal renal function and were discharged to either their new homes or to the rehabilitation centers.

\section{DISCUSSION}

Hyperbaric oxygen therapy is defined as a treatment in which a patient is intermittently exposed to $100 \%$ oxygen while the treatment chamber is pressurized to a pressure above sea level (>1 ATA, $760 \mathrm{mmHg}$ ) [20].

Hyperbaric oxygen therapy was first documented in 1662 when Henshaw built the first hyperbaric chamber [21]. Thereafter HBO therapy has been used in a number of diseases including acute carbon monoxide poisoning, gas gangrene, chronic refractory osteomyelitis, decompression sickness, air embolism and crush injury with a proven efficacy in a limited number of disorders $[20,22]$.

Crush syndrome was first described by Bywaters and Beall in 1940 during World War II and afterwards it was reported in many disasters such as earthquakes, car accidents, war crimes and terrorist acts [2]. Musculoskeletal injuries secondary to crush, blast and penetrating trauma each produce local tissue ischemia, hypoxic gradients from zones of necrotic to healthy tissue and, when inadequately treated, the potential for propagation of ischemic injury into adjacent healthy tissues [23]. Surgery remains one of the treatment strategies for these injuries. Reduction of edema, protection from reperfusion injury, and enhanced wound healing are postulated benefits of adjunctive therapy with hyperbaric oxygen [20].

Effectiveness of hyperbaric oxygen therapy in crush injury due to earthquake has been reported after the Marmara earthquake by the Haydarpasa Military Academy localized in Istanbul. Yildiz et al. [24] reported that 630 patients were admitted to their hospital. Many dif- 
ferent surgical procedures were performed in 146 patients. These procedures included 92 fasciotomies for compartment syndrome, 3 femoral artery repairs and 5 extremity amputations. Among these patients 52 were treated with HBO therapy ( 3 to 70 sessions per patient) in the postoperative period. Similar number of HBO sessions were also noted in our series (2 - 54 sessions per patient). Forty five patients recovered without complication or any sequelae [24]. Amputation of the extremities had to be performed in 5 patients and two patients died due to acute respiratory distress syndrome and sepsis $[24,25]$.

In crush injuries and acute peripheral ischemias perfusion is often so compromised that repair processes ordinarily cannot occur [26]. Specific tissue oxygen tensions are required for neovascularization and fibroblast proliferation. HBO helps achieve these baseline tensions. This is also the proposed mechanism for HBO's usefulness in related conditions such as replantation operations, frostbite and compromised skin grafts [22].

As previously reported by Sever et al. [3] after the Marmara earthquake 639 patients $(12.0 \%)$ suffered from nephrological problems, $477(8.9 \%)$ needed renal replacement therapy and HBO therapy was applied to 28 patients among which 16 were the subjects of this analysis. Application of this strategy did not differ signifycantly between dialyzed versus non-dialyzed patients, while one patients' death was recorded among the patients who were treated with $\mathrm{HBO}(\mathrm{p}=0.022)$ [3].

Hyperbaric oxygen was more effective than no treatment in animals with experimentally induced ischemia and compartment syndromes $[18,20,27]$. Although many case reports and case series suggest a benefit of hyperbaric oxygen, it has not been compared with normobaric oxygen in patients or animals with acute traumatic ischemic injury [27]. Perioperative protocols involve treatment at pressures ranging from 2.0 to 2.8 atmospheres for up to two hours [20]. Our treatment strategy was also to perform a HBO session at 2.4 ATA lasting for 90 minutes in a closed multiplace chamber.

In ischaemic rat tissues, HBO was shown to inhibit neutrophil adherence to the wall of ischaemic vessels and to decrease post-ischaemic vasoconstriction in skin grafts [12]. Furthermore, it was shown that HBO has striking beneficial anti-inflammatory effects on experimental colitis in rats [12].

In trauma of the extremities, a circulatory insufficiency with total and subtotal ischemia may occur. The beneficial effect of HBO therapy is due to high arteriolar oxygen content and oxygen diffusion, thus leading to both enhanced wound healing by fibroblast and capillary proliferation and prevention of infection notably due to anerobic microorganisms [7,18,21]. In our series similar effects were also observed though not statistically significant (Figures 1 and 2). Moreover; HBO produces

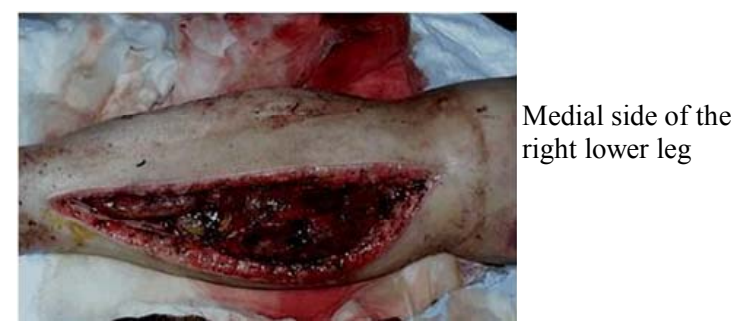

Figure 1. The fasciotomy lesion of a patient before HBO.

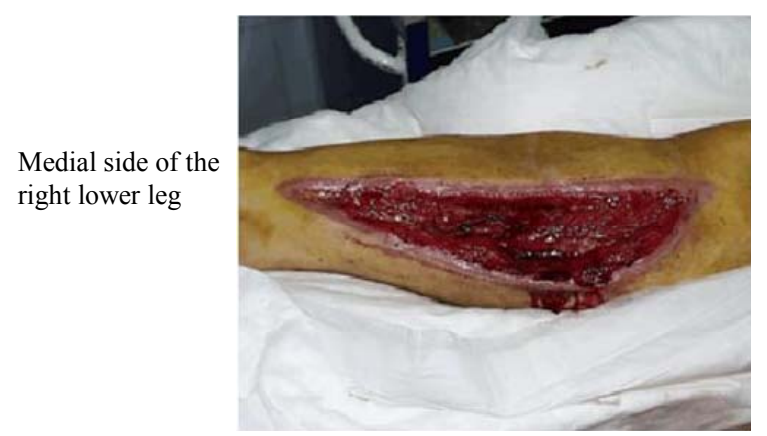

Figure 2. The lesion after $34 \mathrm{HBO}$ sessions.

vasoconstriction and reduces blood flow which leads to the prevention of postischemic edema [21]. Furthermore, this stabilizes the capillary hydrostatic pressure and the vascular permeability. The potentially negative vasoconstrictive effect of oxygen delivery is overcome with the hyperoxygenation. As a result, fluid leakage from the intravascular compartment decreases; the intravascular volume gets maintained and an improvement of renal hemodynamics and renal function can be observed [20-22].

When used according to standard protocols, with oxygen pressures not exceeding 3 atmospheres and treatment sessions limited to a maximum of 120 minutes, hyperbaric therapy is not dangerous [20,21]. Complications such as oxygen toxicity, middle ear barotrauma and confinenment anxiety are well controlled with appropriate preexposure orientations, medications and treatment schedules [21]. None of our patients had any complications related to the $\mathrm{HBO}$ treatment itself.

The findings of Better's animal model provide novel information on the mechanisms underlying acute renal failure and support the use of HBO for treatment of ischaemic renal injury [12]. In their study renal ischaemia was induced by unilateral renal artery clamping in rats and within 24 hours following ischaemia, rats were treated twice with $\mathrm{HBO}$ of $100 \% \mathrm{O}_{2}$ at 2.5 absolute atmospheres for 90 minutes each [12]. Untreated rats had served as a control. Forty-eight hours after HBO treatment glomerular filtration rate, renal blood flow and endothelial-dependent vasorelaxation were measured in both groups revealing better results in the HBO treated group. The HBO-induced renal vasodilatation was associated with a significant increase in total renal blood flow in response to acetylcholine due to enhanced perfusion of 
the renal cortex in the ischaemic kidney [12].

\section{CONCLUSIONS}

Our results could not demonstrate a significant effect of HBO treatment in terms of HD duration. This could be attributed to the fact that our sample size was too little. Rubinstein et al. [12] had demonstrated that despite the improvement in renal hemodynamics, HBO did not cause a concomitant increase in urine flow or sodium excretion in their animal model.

Moreover, the most important and valuable contribution of HBO treatment was the avoidance of repetitive surgical interventions and most likely amputations in the victims [21]. A decade ago, HBO was described as "a therapy in search of diseases" [28]. The discovery of beneficial cellular and biochemical effects has strengthened the rationale for administering HBO as primary and/or adjunctive therapy in many conditions including the management of crush injuries encountered during natural disasters.

\section{REFERENCES}

[1] Tonelli, M., Manns, B. and Feller-Kopman, D. (2002) Acute renal failure in the intensive care unit: A systematic review of the impact of dialytic modality on mortality and renal recovery. American Journal of Kidney Diseases, 40, 875-885. doi:10.1053/ajkd.2002.36318

[2] Sever, M.S., Vanholder, R. and Lameire, N. (2006) Management of crush-related injuries after disasters. The New England Journal of Medicine, 354, 1052-1063.

[3] Sever, M.S., Erek, E., Vanholder, R., Koc, M., Yavuz, M., Ergin, H., Kazancioğlu, R., Serdengecti, K., Okumus, G., Ozdemir, N., Schindler, R. and Lameire, N. (2002) Treatment modalities and outcome of the renal victims of the Marmara earthquake. Nephron, 92, 64-71.

doi:10.1159/000064487

[4] Jacob, A.I., Gavellas, G., Zarco, R., Perez, G. and Bourgoignie, J.J. (1980) Leukopenia, hypoxia, and complement function with different hemodialysis membranes. Clinical Investigation, 18, 505-509. doi:10.1038/ki.1980.164

[5] Smith, J.C., and Jones, J.G. (1993) Oxygen saturation during hemodialysis. Renal Failure, 15, 239-245. doi:10.3109/08860229309046158

[6] Cardoso, M., Vinay, P., Vinet, B., Leveillee, M., Prud'homme, M., Tejedor, A., Courteau, M., Gougoux, A., StLouis, G., Lapierre, L. and Piette, Y. (1988) Hypoxemia during hemodialysis: A critical review of the facts. American Journal of Kidney Diseases, 11, 281-297.

[7] Nylander, G., Nordstrom, H., Lewis, D. and Larsson, J. (1987) Metabolic effects of hyperbaric oxygen in postischemic muscle. Plastic and Reconstructive Surgery, 79, 91-97. doi:10.1097/00006534-198701000-00015

[8] Zamboni, W.A., Wong, H.P. and Stephenson, L.L. (1996) Effect of hyperbaric oxygen on neutrophil concentration and pulmonary sequestration in reperfusion injury. Ar- chives of Surgery, 131, 756-760. doi:10.1001/archsurg.1996.01430190078020

[9] Buras, J.A., Stahl, G.L., Svoboda, K.K.H. and Reenstra, W.R. (2000) Hyperbaric oxygen downregulates ICAM-1 expression induced by hypoxia and hypoglycemia: The role of NOS. American Journal of Physiology-Cell Physiology, 278, C292-C302.

[10] Yamashita, M. and Yamashita, M. (2000) Hyperbaric oxygen treatment attenuates cytokine induction after massive hemorrhage. American Journal of Physiology, Endocrinology and Metabolism, 278, E811-E816.

[11] Sheikh, A.Y., Gibson, J.J., Rollins, M.D., Hopf, H.W., Hussain, Z. and Hunt, T.K. (2000) Effect of hyperoxia on vascular endothelial growth factor levels in a wound model. Archives of Surgery, 135, 1293-1297. doi:10.1001/archsurg.135.11.1293

[12] Rubinstein, I., Abassi, Z., Milman, F., Ovcharenko, E., Coleman, R., Winaver, J. and Better, O.S. (2009) Hyperbaric oxygen treatment improves GFR in rats with ischaemia/reperfusion renal injury: A possible role for the antioxidant/oxidant balance in the ischaemic kidney. $\mathrm{Ne}$ phrology Dialysis Transplantion, 24, 428-436. doi:10.1093/ndt/gfn511

[13] Solmazgul, E., Uzun, G., Cermik, H., Atasoyu, E.M., Aydinoz, S. and Yildiz S. (2007) Hyperbaric oxygen therapy attenuates renal ischemia/reperfusion injury in rats. Urology International, 78, 82-85. doi:10.1159/000096941

[14] James, P.B. (1994) Hyperbaric oxygen treatment for crush injury. British Medical Journal, 309, 1513. doi:10.1136/bmj.309.6967.1513b

[15] Hamilton-Farrell, M.R. (1994) Hyperbaric oxygen in crush syndrome. British Medical Journal, 309, 1582-1583. doi:10.1136/bmj.309.6968.1582c

[16] Bouachour, G., Cronier, P., Gouello, J.P., Toulemonde, J.L., Talha, A. and Alquier, P. (1996) Hyperbaric oxygen therapy in the management of crush injuries: A randomized double-blind placebo-controlled clinical trial. Journal of Trauma, 41, 333-339. doi:10.1097/00005373-199608000-00023

[17] Myers, R.A. (2000) Hyperbaric oxygen therapy for trauma: Crush injury, compartment syndrome, and other acute traumatic peripheral ischemias. International Anesthesiology Clinics, 38, 139-151. doi:10.1097/00004311-200001000-00009

[18] Skyhar, M.J., Hargens, A.R., Strauss, M.B., Gershuni, D.H., Hart, G.B. and Akeson, W.H. (1986) Hyperbaric oxygen reduces edema and necrosis of skeletal muscle in compartment syndromes associated with hemorrhagic hypotension. The Journal of Bone \& Joint Surgery, 68, 12181224.

[19] Reis, N.D. and Better, O.S. (2005) Mechanical musclecrush injury and acute muscle-crush compartment syndrome: With special reference to earthquake casualties. The Journal of Bone \& Joint Surgery, 87, 450-453. doi:10.1302/0301-620X.87B4.15334

[20] Tibbles, P.M. and Edelsberg, J.S. (1996) Hyperbaric oxygen therapy. The New England Journal of Medicine, 334, 1642-1648. doi:10.1056/NEJM199606203342506 
[21] Gill, A.L. and Bell, C.N.A. (2004) Hyperbaric oxygen: Its uses, mechanisms of action and outcomes. Quarterly Journal of Medicine, 97, 385-395. doi:10.1093/qimed/hch074

[22] Strauss, M.B. (1982) The role of hyperbaric oxygen in orthopedics. The Western Journal of Medicine, 137, 413414.

[23] Warriner, R.A. and Hopf, H.W. (2003) Hyperbaric Oxygen Therapy Committee Report 2003-Healing in problem wounds. In: Feldmeier, J.J., Ed., Hyperbaric Oxygen 2003: Indications and Results: The Hyperbaric Oxygen Therapy Committee Report, Undersea Hyperbaric Medical Society, Kensington, 41-55.

[24] Yildiz, S., Ozkan, S., Dundar, K., Ay, H., Kiralp, M.Z. and Pehlivan, O. (2004) Hyperbaric oxygen therapy in crush injuries after 17th of August earthquake in Marmara. Gülhane Tıp Dergisi, 46, 194-199.
[25] Us, M.H., Rodop, O., Özkan, S., Civelek, A., Elbuken, E., Inan, K., Sungun, M. and Ozturk, O.Y. (2000) Our experiences in treatment of compartment syndrome after 17 August earthquake. Turkish Journal of Thoracic and Cardiovascular Surgery, 8, 805-807.

[26] Strauss, M.B. (1981) Role of hyperbaric oxygen therapy in acute ischemias and crush injuries-An orthopaedic perspective. HBO Review, 2, 87-106.

[27] Strauss, M.B., Hargens, A.R., Gershuni, D.H., Greenberg, D.A., Crenshaw, A.G., Hart, G.B. and Akeson, W.H. (1983) Reduction of skeletal muscle necrosis using intermittent hyperbaric oxygen in a model of compartment syndrome. The Journal of Bone \& Joint Surgery, 65, 656-662.

[28] Gabb, G. and Robin, E.D. (1987) Hyperbaric oxygen: A therapy in search of diseases. Chest, 92,1074-1082. doi:10.1378/chest.92.6.1074 